REVIEW

\title{
Complications of coeliac disease: are all patients at risk?
}

\author{
C J R Goddard, H R Gillett
}

Postgrad Med J 2006;82:705-712. doi: 10.1136/pgmi.2006.048876

Coeliac disease is a common condition that is increasingly being recognised as a result of the development of sensitive and specific serology. The diagnosis of coeliac disease and its subsequent treatment with a gluten-free diet have implications for the patient, not just for symptom control but also for the possible effect on quality of life and risk of complications. Whether the mode of presentation of coeliac disease has an effect on survival or risk of complication is yet unclear. This article reviews the available evidence regarding these issues.

See end of article for authors' affiliations

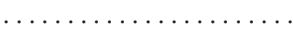

Correspondence to: H R Gillett, St John's Hospital, Howden Road West, Livingston, West Lothian EH54 6PP, UK; helen.gillett@wlt.scot.nhs. co.uk

Received 18 April 2006 Accepted 25 May 2006
C oeliac disease is a permanent glutensensitive enteropathy characterised by reversible small-bowel mucosal atrophy in a genetically predisposed person. Samuel Gee first described the classic presentation with malabsorption in 1888: "the coeliac affection", but it was not until the late 1940s that Dicke, a Dutch paediatrician, first recognised that the ingestion of wheat was responsible for manifestation of the disease. ${ }^{2}$ In recent years, a series of studies has shown that coeliac disease is far more common than previously thought; moreover, the clinical presentation has changed, with many and experiencing minimal symptoms. The purpose of this article is to review critically the current evidence behind the dogma that all patients, whether symptomatic or not, should adhere to a strict gluten-free diet (GFD) after a diagnosis of coeliac disease to avoid complications.

\section{THE "COELIAC ICEBERG"}

It is now apparent that patients presenting with the classic features of malabsorption, weight loss and steatorrhoea represent a small proportion of the total population of patients with coeliac disease. Coeliac disease is a heterogeneous condition in which most patients present with vague symptoms such as chronic diarrhoea, abdominal bloating and tiredness. Some patients may have virtually no symptoms. Over 10 years ago, Professor Anne Ferguson ${ }^{3}$ first compared the total population of patients with coeliac disease with an iceberg having only a small proportion visible above the water line (ie, those patients with overt clinical disease), but a far greater proportion, not immediately visible, below the water line (those with silent, potential and latent disease). Ferguson defined patients with "silent disease" as those who have characteristic intestinal changes of coeliac disease, which return to normal on a GFD, without manifesting clinical symptoms; patients with "latent coeliac disease" patients presenting with the disease in adulthood as those who have normal small-bowel mucosa on a normal diet but who have had or will have an abnormal finding on biopsy, which recovers on a GFD; and patients with "potential coeliac disease" as those who have had positive serology, morphometric studies or family history with normal intestinal histology.

THE CHANGING SHAPE OF THE ICEBERG Partly related to the increased awareness of the heterogeneity of coeliac disease and partly also due to the improvement in sensitivity and specificity of serological tests, there has been a huge increase in the reported prevalence of coeliac disease in many countries over the past 10 years. In Europe this figure is now between 2 and 20 per 1000 people. ${ }^{4-6}$ Although there is some variability, most studies report an approximate 2:1 to $3: 1$ predominance of women. The diagnosis of coeliac disease is now more commonly made in adulthood than in childhood, with as many as $50 \%$ of adults diagnosed aged $>50$ years. ${ }^{29}$ The prevalence is even higher in those with type 1 diabetes, ${ }^{30}$ Down's syndrome, ${ }^{31}$ Turner syndrome ${ }^{32} 33$ and Williams syndrome, ${ }^{34}$ and arguments can be made for screening these people.

The question of whether there has been a true increase in the incidence of coeliac disease is clearly important but difficult to answer with any confidence. In Sweden, there was a dramatic increase in reported incidence in infants from 50 to 200 cases per 100000 between 1985 and 1987. The incidence sharply decreased back to the original levels from 1995 onwards. This variation was attributed to changes in the age of introduction and amounts of gluten in infants' diets. ${ }^{35} 36$ The reported incidence of adult coeliac disease in South Wales increased by more than twofold between 1981 and 1995, but over the same period the incidence of childhood coeliac disease and dermatitis herpetiformis, which is usually diagnosed early as a result of intense itching of skin lesions, remained the same. The authors concluded that true incidence was not increasing in adults, but doctors were more alert to the diagnosis. ${ }^{29}$ A similar conclusion was reached in a Finnish study where the incidence of coeliac disease increased 10-fold over a 20-year period, but the incidence of dermatitis herpetiformis remained stable. ${ }^{6}$

Population-based screening studies suggest that as many as $50-90 \%$ of people with coeliac disease, the body of the iceberg, are living undiagnosed in the community. ${ }^{4-16}$ In Catassi's population screening studies in Southern Italy,

Abbreviations: $B M D$, bone mineral density; GFD, glutenfree diet; SMR, standardised mortality ratio 


\begin{tabular}{|c|c|c|c|}
\hline Country, first author, year & $\begin{array}{l}\text { Patients/ } \\
\text { diagnosis }\end{array}$ & Methods & Malignancy/relative risk \\
\hline USA, Green, ${ }^{17} 2001$ & $1612 / C D$ & Cohort survey & Lymphoma: 300; adenoma: 67 \\
\hline Scotland, Ferguson, ${ }^{18} 1996$ & $653 / \mathrm{CD}$ & Cohort survey & Lymphoma: 31 ; oesophagus: 8 \\
\hline Finland, Collin, 1994 & $335 / C D$ & Cohort study & No increased risk \\
\hline Finland, Collin, ${ }^{20} 1996$ & 305/ DH & Cohort study & Lymphoma: 10.3 \\
\hline USA, Delco, 1999 & $458 / C D$ & Case control study & Lymphoma: 4.5 \\
\hline UK/Finland, Lewis, ${ }^{22} 1996$ & $487 / \mathrm{DH}$ & Cohort survey & Lymphoma:80 \\
\hline $\begin{array}{l}\text { Sweden/Iceland, } \\
\text { Sigurgeirsson, }{ }^{23} 1994\end{array}$ & 976/ DH & $\begin{array}{l}\text { National disease } \\
\text { registry }\end{array}$ & Lymphoma: 5.4 \\
\hline UK, Swinson, ${ }^{24} 1983$ & $\begin{array}{l}\text { 235/ } \\
\text { CD+tumour }\end{array}$ & $\begin{array}{l}\text { Pathology records } \\
\text { review }\end{array}$ & Lymphoma, small-bowel adenoma: 83 \\
\hline $\begin{array}{l}\text { UK, Cooper, }{ }^{25} 1982 \\
\text { Holmes }{ }^{26} 1989\end{array}$ & $210 / C D$ & Cohort study & $\begin{array}{l}\text { Lymphoma: } 42 \text {; oesophagus: } 12 \text {; } \\
\text { oropharynx: } 9.7\end{array}$ \\
\hline Australia, Selby, 1979 & $93 / C D$ & Cohort study & Lymphoma: 50 ; oesophagus: 200 \\
\hline Italy, Catassi, 2002 & $653 / \mathrm{NHL}$ & Cohort study & CD in $0.92 \%$; Odds ratio, EATL: 19 \\
\hline
\end{tabular}

$\mathrm{CD}$, coeliac disease; DH, dermatitis herpetiformis; EATL, entopathy-associated T-cell lymphoma; NHL, nonHodgkin's lymphoma.

only one third of the people found with coeliac disease were asymptomatic; the rest were found to have iron deficiency, tiredness, irritability, depression, abdominal pains, apthous stomatitis, diarrhoea, flatulence and a variety of other problems that tended to improve on a GFD. ${ }^{10} 37$ This finding of high numbers of patients with symptoms by screening is remarkably consistent. ${ }^{4-7} 11131437$ When patients with symptoms of irritable bowel or anaemia are screened, the incidence of coeliac disease in this population rises to 30 per 1000 people..$^{38}$ In a large, multicentre, retrospective study on Italian patients with "subclinical and silent" coeliac disease, only $20 \%$ of the cohort was truly asymptomatic; the remainder had iron deficiency, dermatitis herpetiformis, neurological problems, short stature, apthous stomatitis, osteoporosis and many other problems. ${ }^{39}$ Evidence, therefore, does not confirm the assumption by Ferguson and other investigators that the large group of people with coeliac disease who remain undiagnosed have either no or minimal symptoms that do not interfere with their lives.

\section{DOES THE SHAPE OF THE ICEBERG MATTER?}

To answer this question, we need to critically review the current literature regarding the incidence of the various complications of long-term coeliac disease with respect to the heterogeneity of this condition. When evaluating these data, it is important to understand the lack of a universal definition for "symptomatic" and "asymptomatic" with regard to patients with coeliac disease. In addition, no reliable, objective assessment of compliance with GFD is currently available.

\section{Quality of life}

Arguably, most people with either diagnosed or undiagnosed coeliac disease have only minor symptoms that are more inconvenient than life threatening, but is this really true? The few data available regarding quality of life of patients with coeliac disease suggest that health-related quality of life and psychological general well-being are poor in undiagnosed patients, and improve with treatment in men but not significantly in women. This difference between sexes was explained by a greater reporting of symptoms by women in remission, implying factors beyond normalisation of the intestinal mucosa. ${ }^{40}{ }^{41}$ In the US, 1612 respondents to a postal questionnaire reported a mean duration of symptoms for 11 years before the diagnosis of coeliac disease was made; after treatment $77 \%$ had an improved quality of life. ${ }^{17}$ A high prevalence of depression was well documented in patients with coeliac disease. ${ }^{42}$ In comparison with controls, anxiety and depression are much more common (71\% v 23\%; $\mathrm{p}<0.001$ and $57 \% \vee 10 \% ; \mathrm{p}<0.001$, respectively) and tend to improve, but not normalise, after 1 year on a GFD. ${ }^{43}$

\section{Survival}

Several papers have tried to tackle the difficult issue of survival in patients with coeliac disease. One hundred patients were followed up in Denmark for 18 years. This cohort had a standardised mortality ratio (SMR; the ratio of observed to expected deaths) of 3.4 when compared with the general population $(\mathrm{p}<0.025) .{ }^{44}$ Of concern, apart from an increased risk of mortality from malignancy, there was also a high death rate from suicide ( 3 deaths, 2 of which were related to intractable symptoms), diabetes ( 5 deaths) and inflammatory bowel disease (2 deaths). Ferguson's group in Edinburgh found an SMR of 1.9 in 653 patients with coeliac disease (95\% confidence interval (CI) 1.5 to $2.2 ; \mathrm{p}<0.001$ ). The increased mortality was observed principally in the first year of diagnosis of coeliac disease in 45-65-year-old patients and was mostly related to the development of lymphomas. ${ }^{45} 18$

A smaller Finnish study followed up 335 patients with coeliac disease for 10 years and found no increase in mortality. ${ }^{19}$ The same investigators also followed up 305 patients with dermatitis herpetiformis for 20 years. Although there was an increased risk of malignancy in patients with dermatitis herpetiformis, they found a survival similar to that in the general population. ${ }^{20}$ They attributed the normal mortality in these two cohorts to a high proportion of strict adherers to GFD ( $>90 \%$ in both groups) and regular attendance at a specialist clinic where dietary advice was available.

The most robust study on mortality in recent years was based in Italy. ${ }^{46} \mathrm{~A}$ cohort of 1072 patients with coeliac disease and another of 3384 first-degree relatives were followed up for about 35 years from diagnosis and expected mortality was compared. In the whole coeliac disease group, the SMR was 2.0 (95\% CI 1.5 to 2.7 ). A significant excess in mortality was seen in the first 3 years after diagnosis and in patients who presented with malabsorption (SMR 2.5, 95\% CI 1.8 to 3.4 ), but not in those who presented with minor symptoms (SMR $1.1,95 \%$ CI 0.5 to 2.2 ), or who were asymptomatic and were diagnosed after antibody screening (SMR 1.2, 95\% CI 0.1 to 7.0). The mortality was high (SMR 3.8, 95\% CI 2.2 to 6.4 ) in patients in whom the diagnosis was delayed for $>10$ years after the onset of symptoms, but highest in patients not adherent to GFD (SMR 6.0, 95\% CI 4.0 to 8.8). There was no increased mortality in the relatives of patients with coeliac disease. The increased mortality seen in patients with coeliac disease was mainly due to malignancy. 
Most available data therefore point towards a decreased life expectancy in those diagnosed late in life, with severe symptoms and who fail to adhere to a GFD. However, whether most people with coeliac disease who remain undiagnosed in the community, not following a GFD, have a normal or reduced life expectancy, is yet unclear.

\section{Malignancy}

Unfortunately, owing to the difficulties in studying the incidence of malignancy in patients with coeliac disease, few studies in the literature have considered this important issue. ${ }^{17-28}$ The design of these studies mostly involved analysis of cohorts identified retrospectively and the studies are therefore open to methodological criticism. Few have explored the differences between symptomatic and asymptomatic disease, and few data exist regarding the influence of compliance with a GFD.

The best known data regarding malignancy in coeliac disease come from a series of studies from Derby, UK. Holmes et al followed up a cohort of 210 patients with coeliac disease for a mean of 19 years ${ }^{25} 2647$ between 1972 and 1985. A total of 39 cancers had developed in the group, with 33 malignancy-related deaths. The expected numbers of tumours were calculated from the local cancer registry. Overall, patients with coeliac disease had an increased risk of developing oropharyngeal cancer (relative risk (RR) 9.7, $\mathrm{p}<0.01,95 \%$ CI 2.0 to 28.3), oesophageal cancer (RR 12.3, $\mathrm{p}<0.01,95 \%$ CI 2.5 to 36.5 ) and non-Hodgkin's lymphoma (RR 42.7, p<0.001, 95\% CI 19.6 to 81.4). In patients who had been on a GFD for $>5$ years, the risk of malignancy was no higher than that in the general population. However, in those not adhering to the diet, the risks of developing malignancy were much increased (oropharangeal and oesophageal cancer, RR 22.7, $\mathrm{p}<0.001$; and lymphoma, RR 77.8, $\mathrm{p}<0.001)$. Importantly, the method of assessing the dietary compliance is not stated, but seems to be an estimation from case note review. This cohort of patients was, of course, collected in the early 1970s, at a time when most patients would have had major symptoms leading to the diagnosis of coeliac disease. More recently, however, Card et al ${ }^{48}$ reported long-term follow-up data from a cohort of patients with treated coeliac disease, and found a lower risk of small-bowel lymphoma than previously thought (1 patient with 0.02 expected).

Several retrospective cohort studies have compared observed rates of malignancy with calculated expected rates in different populations; all have identified a markedly increased risk of lymphoma in patients with coeliac disease (RR approximately 30-50). ${ }^{18274950}$ A more recent, casecontrol study of 458 patients with coeliac disease from the Veterans Administration in the USA estimated a 4.5 -fold increased risk (95\% CI 2.0 to 10.2 ) of developing lymphoma. ${ }^{21}$ In this study, the cases and controls were poorly matched for age and race, which may have affected the outcome. In addition, most of the study subjects were men (96\%). A postal survey of 1612 patients with coeliac disease yielded a greatly increased risk of lymphoma (300 times that expected), but obviously these findings are subject to reporting bias. ${ }^{17}$ A retrospective multicentre review from the UK pathological archives, to identify malignancies associated with coeliac disease, reported a considerably increased number of lymphomas and small-intestinal adenocarcinomas than expected. ${ }^{24}$ No reduction in the risk of lymphoma was evident in patients who showed a good histological response to a GFD. This increased risk of malignancy was not seen when a Finnish group studied 335 patients with coeliac disease followed up for only 5 years. ${ }^{19}$

The Italian Working Group on Coeliac Disease and nonHodgkin's lymphoma examined the association from the opposite perspective. These authors gathered 653 patients who had been diagnosed as having non-Hodgkin's lymphoma and examined them for coeliac disease. The prevalence of coeliac disease in this group was $0.92 \%$, the odds ratio (OR) for non-Hodgkin's lymphoma of any primary site related to coeliac disease was 3 and for enteropathyassociated T-cell lymphoma related to coeliac disease was $19^{28}$

Although gastrointestinal symptoms are unusual in dermatitis herpetiformis, as many as $80 \%$ of patients with dermatitis herpetiformis will have changes consistent with coeliac disease on small-bowel biopsy. ${ }^{20}$ Owing to this close association between coeliac disease and dermatitis herpetiformis, it is particularly relevant to consider the literature on the malignant complications of dermatitis herpetiformis. The first to identify an association was a retrospective review of 109 patients with dermatitis herpetiformis from the UK. ${ }^{51}$ Three patients developed lymphoma, giving a RR of 100 above the expected incidence. Importantly, in those patients taking a normal diet the overall RR of developing any malignancy was 3.09 (95\% CI 1.65 to 4.53 ), whereas in those on a GFD, there was no increased risk. Sigurgeirsson et al ${ }^{23}$ reported the incidence of malignancy in 976 patients with dermatitis herpetiformis and found a RR of 5.4 (95\% CI 2.2 to 11.1) for the development of lymphoma, but found no increased risk of developing other malignancies. The number of patients adhering to a GFD was not stated, subjects were identified from a database of hospital admissions, and patients "with concomitant coeliac disease" were excluded. All these factors may have influenced the results. ${ }^{23}$ In a collaborative study between the UK and Finland, a retrospective analysis of 487 patients found an increased risk of development of lymphoma in dermatitis herpetiformis (RR 38.1, 95\% CI not stated); however, there were no lymphomas found in patients who were established on a GFD for $>5$ years. $^{22}$ Finally, a Finnish study found a 10 times increased risk of lymphoma above expected (95\% CI 2.8 to 26.3) in 305 patients with dermatitis herpetiformis with a mean follow-up of 9.9 years. ${ }^{20}$ Interestingly, in this study, although $93 \%$ of the patients adhered to a GFD, three of the four lymphomas seen were diagnosed in patients who had been treated for $<5$ years.

In summary, there is little doubt that coeliac disease and dermatitis herpetiformis are associated with a greatly increased risk of developing small-bowel lymphoma (enteropathy-associated T-cell lymphoma; RR between 5 and 100) and also probably oesophageal and small-bowel adenocarcinomas, and oropharyngeal tumours (table 1). It also seems likely that taking a GFD is protective against the development of malignancy in both these conditions. A crucial question that needs answering if patients are to be managed optimally is whether the severity of the presenting clinical picture correlates to the risk of developing malignancy. Unfortunately, none of the above studies have dealt with this issue directly. It may be relevant that the risk of developing lymphoma in both coeliac disease and dermatitis herpetiformis seems to be equal, despite the fact that gastrointestinal symptoms are unusual in dermatitis herpetiformis. Also, enteropathy-associated T-cell lymphomas often present in middle-aged patients who have previously been unknown to have coeliac disease, ${ }^{52}$ implying that their disease was minimally symptomatic. Arguably, although the risk of enteropathy-associated T-cell lymphoma is greatly increased in coeliac disease, in any individual patient this complication is still unlikely to occur. The other side of this argument, however, is the dismal prognosis of the disease. Even with aggressive chemotherapy, the 1-year survival after diagnosis is about $30 \%$ and 5 -year survival $10 \% .{ }^{185354}$ To complicate the issue further, enteropathy-associated T-cell 
lymphoma is extremely difficult to diagnose, having similar histological appearances as active coeliac disease. Indeed, it has been suggested that a high proportion of patients diagnosed as having adult coeliac disease, especially $>50$ years have a low-grade lymphoma and not coeliac disease at all..$^{55}$

\section{Osteoporosis}

There are many data which show that coeliac disease is associated with a decreased bone mineral density (BMD). ${ }^{56-66}$ The World Health Organization defines osteopenia as a $\mathrm{T}$ score (number of standard deviations of patient's bone density below that of the young adult mean) of between -1 and -2.5 , and osteoporosis as a T score of $<-2.5$ on BMD scanning. Most studies confirm that approximately one third of adults are osteopenic, one third are osteoporotic and only one third have normal bone density at diagnosis of coeliac disease. The risk of low BMD seems to rise with increasing age at diagnosis, decreased body weight and in postmenopausal women. ${ }^{56-6167}$ Low BMD can be detected even in children and adolescents with newly diagnosed coeliac disease. ${ }^{62}{ }^{64} 68$ To date, the one study which has examined the potentially important question on the prevalence of coeliac disease in idiopathic osteoporosis looked at 100 consecutive patients attending a specialist endocrine clinic. No association was found. ${ }^{69}$

The question as to whether the severity of the symptoms relates to the degree of bone loss has been specifically dealt with only in a few studies. Valdimarsson et $a^{l^{63}}$ reported 13 patients with persistent villous atrophy and noticeable osteopenia. Most were not compliant with GFD as their symptoms were only mild. ${ }^{63}$ The same group later found that in a cohort of 63 patients with coeliac disease, although very low BMD was seen in $20 \%$, symptom severity (ie, presence of symptoms of malabsorption) had no influence on BMD. ${ }^{56}$ Mazure et al, ${ }^{70}$ however, when directly comparing symptomatic to asymptomatic patients found that the symptomatic patients had significantly lower BMD. ${ }^{70}$

In idiopathic osteoporosis, with each standard deviation reduction of BMD below the age and sex-matched mean $(\mathrm{Z}$ score) there is a twofold increased risk of fractures. ${ }^{71}$ An important question to answer is whether the low BMD seen in coeliac disease is similarly associated with an increased risk of fracture. A study from the UK reported a group of 75 patients with coeliac disease; $21 \%$ had a history of fractures, with an increased RR of 7 (95\% CI not quoted) when compared with a matched control group. A poor correlation was found between BMD and fracture risk, implying the contribution of other factors such as poor bone quality. This risk was highest in older patients, before the diagnosis of coeliac disease was made. ${ }^{72}$ In a larger cohort of 165 patients with coeliac disease from Argentina, 25\% gave a history of previous fractures. When compared with controls, the RR for fractures was 3.5 (95\% CI 1.8 to $7.2, \mathrm{p}<0.000)$. Again most fractures $(80 \%)$ were detected before the diagnosis of coeliac disease and in subjects non-compliant with GFD. There was a trend towards a lower spinal and total skeletal BMD in those with fractures. ${ }^{73}$ A group from the UK surveyed 244 patients with coeliac disease by postal questionnaire. They found no marked increase in the risk of fractures, however, it seems that the patients had all been followed up in specialist clinics and presumably most will have been taking GFD, although this is not stated. Also, response bias might have led to a lower return from non-compliers with GFD and therefore underestimated the fracture risk. ${ }^{74}$ A large national survey from Denmark of 1020 patients with coeliac disease failed to show any markedly increased risk of fractures either before or after the diagnosis was made. The relatively low validity of the diagnostic criteria and the fact that the patients were identified through their National Register of hospital discharges may have influenced this study. ${ }^{75}$ In contrast, a study from Argentina found a higher prevalence of fractures in classically symptomatic patients compared with subclinical or silent disease (OR 3.6, 95\% CI 1.7 to 7.5$).{ }^{76}$

Several prospective studies have examined BMD at diagnosis of coeliac disease and after GFD. ${ }^{56} 596577$ All agree that there is a marked increase in BMD after starting a GFD. This improvement seems to be mainly within the first year of treatment. ${ }^{65}$ However, the BMD rarely seems to return to normal and there is a large interindividual variability in response. Valdimarsson's study of 63 patients found that BMD increased in patients with coeliac disease after 1 year of GFD irrespective of patient's age and the presence of malabsorption. ${ }^{56}$ Conversely, Ciacci et al $7^{77}$ found that increase in BMD after 1 year of GFD could be predicted by the patient's age, sex and pretreatment BMD. In children and adolescents with coeliac disease the low BMD seen in newly diagnosed patients can be returned to normal with 1 year of GFD. ${ }^{62}{ }^{69}$

Most evidence points towards the conclusion that all patients with untreated coeliac disease are at risk of low $\mathrm{BMD}$, irrespective of age and severity of symptoms. Although the current available evidence is rather contradictory, it seems that this low BMD is associated with an increased risk of fragility fractures in those not started on GFD. Once on a GFD, the risk of fractures diminishes and the earlier patients are started on treatment with a GFD, the better the response will be. The standard drug treatments for osteoporosis (calcium, vitamin D and bisphosphonates), although often used in patients with coeliac disease, cannot be relied on, as there are no data in the literature regarding their use in these people.

\section{Reproduction}

There is growing evidence to prove that coeliac disease may affect reproduction at various points in both men and women. In a study of 28 male patients with coeliac disease, it was found that sexual activity was significantly lower than in matched controls $(p<0.5)$, but became more frequent after treatment with a GFD. ${ }^{78}$ This early finding was confirmed by an Italian study of 51 patients with coeliac disease surveyed before and after starting a GFD. Men and women, symptomatic and asymptomatic, all had a significantly lower frequency of intercourse $(\mathrm{p}<0.05)$ and a lower prevalence of sexual satisfaction $(\mathrm{p}<0.01)$ compared with controls, which corrected after 1 year of a GFD. ${ }^{79}$

Women with coeliac disease can also have major menstrual problems. One report from Italy of 34 newly diagnosed coeliac women found significantly delayed menarche ( 13.5 years of age $v 12.1$ years; $\mathrm{p}<0.000$ ), more frequent secondary amenorrhoea $(38.8 \% v 9.2 \% ; \mathrm{p}<0.001)$ and a trend towards earlier menopause ( $45.5 v 49.5$ years of age).$^{80}$ This was confirmed by a larger study from Argentina where 130 women with coeliac disease were compared with matched controls. It was found again that patients with untreated coeliac disease had a significantly later menarche (13v 12 years; $\mathrm{p}<0.001)$, more frequent secondary amenorrhoea $(10 \%$ v $1.5 \% ; \mathrm{p}<0.02)$ and earlier menopause ( $45 \vee 50$ years; $\mathrm{p}<0.04)$. However, these women with coeliac disease who adhered strictly to long-term GFD had gynaecological histories identical to the controls. ${ }^{81}$

Examining the issue of infertility in women from a different perspective, Collin et $a l^{82}$ studied women attending a specialist clinic with infertility and normal gynaecological investigations. Out of 150 women, they found four to have coeliac disease compared with none from the control group $(p<0.02)$. None of the four identified with coeliac disease had marked symptoms from the coeliac disease. Similar 
results were obtained from an Italian study of unexplained infertility in women. They found 2 of 25 women to have coeliac disease $(\mathrm{p}<0.03){ }^{83}$

Once pregnant, women with coeliac disease may have a high complication rate. An increased incidence of recurrent spontaneous abortions in patients with untreated coeliac disease has been reported in several studies. In the study by Smecuol et al, ${ }^{81}$ patients with coeliac disease had double the number of abortions than controls ( $19 \% v 10 \%$; $\mathrm{p}<0.02)$, and in Moltini's study ${ }^{80}$ the incidence of recurrent abortions was also significantly higher $(\mathrm{p}<0.03)$. In one large case-control study of 125 pregnant women with coeliac disease, the RR of abortion was 8.9 times higher (95\% CI 1.2 to 66.3 ) in untreated coeliac disease. ${ }^{84}$ Martinelli et a ${ }^{85}$ screened 845 women attending an obstetric clinic. Twelve women with previously unidentified, minimally symptomatic, coeliac disease were found, and of these, seven had an unfavourable outcome due to either low birth weight or miscarriage. ${ }^{85}$ In another study from Italy, undiagnosed coeliac disease was present in $8 \%$ of 40 women with recurrent spontaneous abortions. ${ }^{86}$ Nørgård et $a l^{87}$ reported a series of 211 births to 127 mothers with coeliac disease in Denmark. A significantly increased risk of intra-uterine growth retardation (OR 3.4, $95 \%$ CI 1.6 to 7.2 ) was observed. ${ }^{87}$

The incidence of low birth-weight babies is much higher in patients with untreated coeliac disease than control populations: Ciacci: OR 5.84 (95\% CI 1.1 to 31.9); Nørgård: OR 2.6 (95\% CI 1.3 to 5.5); Ludvigsson: OR 6 (95\% CI 2.6 to 15.8). ${ }^{8487} 88$ In all of the above studies, the incidence of these serious complications was not related to the severity of the coeliac disease, but the risks were dramatically reduced by treatment with GFD. Disturbingly, there is growing evidence to suggest that low birth weight is associated with chronic disease such as ischaemic heart disease and type 2 diabetes later in adult life. ${ }^{89-91}$ Once born, the duration of breast feeding is 2.5 times shorter in patients with untreated coeliac disease. ${ }^{84}$

Farthing's study of men with coeliac disease study found an increased incidence of hypogonadism, sexual dysfunction and poor semen quality in almost half his cohort, resulting in an increased incidence of infertility. ${ }^{78}$ Perhaps more surprisingly, a questionnaire-based study of 10597 births in Sweden found 53 births with their mother with coeliac disease and 27 with a father with coeliac disease. Infants born to fathers with coeliac disease were five times (95\% CI 1.5 to 17.2 ) more likely to have low birth weight, were more likely to be delivered early $(-0.81$ weeks, $95 \%$ CI -1.53 to -0.08$)$ and weighed $266 \mathrm{~g}$ less (95\% CI $-459 \mathrm{~g}$ to $-72 \mathrm{~g}$ ) than the average population. However, the study should be interpreted with caution as only known fathers with coeliac disease were identified and it was assumed that most were following a GFD, although data were not collected regarding this issue. ${ }^{88}$ It might be hypothesised that the outcomes would have been even worse if the fathers had been screened for coeliac disease.

There is little doubt that untreated coeliac disease adversely affects both male and female reproduction. It also seems that patients with minimal symptoms have a considerably increased risk of problems. These complications can cause great distress to couples and may adversely affect the future health of the offspring. Good evidence exists regarding the effectiveness of GFD in returning reproduction to normal. Much rarer diseases than coeliac disease are routinely screened for in pregnant women.

\section{GLUTEN-FREE DIET}

Most gastroenterologists at present recommend a strict GFD in all patients diagnosed with coeliac disease. However, this should not be undertaken without proper consideration. In a survey of 39 patients with coeliac disease aged between 10 and 21 years, it was found that starting a GFD had marked adverse psychological effects with feelings of isolation from and envy towards their peers. ${ }^{92}$ Consequently, after starting a GFD, long-term compliance is often poor. In one Irish audit of 20 young adults with coeliac disease diagnosed in childhood, gluten ingestion varied greatly, with only three patients adhering strictly to the diet. ${ }^{93}$ Even in a group of patients who were active members of a coeliac society in the US, a postal questionnaire showed that only $68 \%$ complied strictly with a GFD, and indeed $23 \%$ reported no improvement or worsening of quality of life after starting a GFD. ${ }^{94}$ It is perhaps unsurprising that the compliance with treatment seems to be worse in patients diagnosed by serological screening than those diagnosed with overt symptoms. ${ }^{94}$

The advice given to patients on the subtleties of GFD is often confusing and contradictory. For example, many dieticians recommend avoidance of oats even though there is growing evidence that oats are safe, ${ }^{95-97}$ and coeliac disease organisations throughout the US and Europe provide widely differing advice regarding foodstuffs, such as millet, buckwheat, distilled vinegar and wheat starch. ${ }^{98}$ Many patients are advised to follow the World Health Organization or Food and Agricultural Organization Codex Alimentarius GFD, which allows up to $0.3 \%$ of gluten per $100 \mathrm{~g}$ of protein in foods, whereas others follow a strict GFD with no detectable gluten. However, trace amounts of gluten may be responsible for persistent symptoms in some patients with coeliac disease. Up to $75 \%$ of patients with persistent symptoms despite a World Health Organization or Food and Agricultural Organization Codex Alimentarius GFD will improve when put on a "no detectable gluten" diet. ${ }^{99}$

The response to treatment with a GFD is conventionally assessed by improvements in symptoms, immunological markers and small-bowel mucosal histology. The smallbowel mucosal histology is regarded by most as the gold standard. As we have highlighted, many patients with coeliac disease have minimal symptoms and therefore in this group of patients, symptoms cannot be used to assess response. The use of serology is controversial. Some papers report that seroconversion of a positive immunoglobulin A anti-endomysial or tissue transglutaminase antibody before treatment to negative after treatment correlates well with histological response, ${ }^{100}$ whereas others report little correlation of disappearance of antibodies with histology..$^{93} 101$ Duodenal biopsy specimens are unpleasant for the patient and expensive and repeated biopsy is no longer our standard practice. Also, there are poor correlations between histological changes and symptom severity ${ }^{93}$ and the amount of gluten ingested in patients with coeliac disease. ${ }^{102}$ Perhaps response to GFD should be assessed by gut function, however, improvements in intestinal permeability precede histological changes by up to 6 months. ${ }^{103}$

Therefore, starting a patient on a GFD may have adverse consequences to their lifestyle. Compliance with the diet can be expected to be poor, especially in patients with minimal symptoms and the precise diet that should be recommended is still controversial. What is more, assessment of response and adherence to treatment is at best difficult.

\section{CONCLUSIONS}

Coeliac disease is an extremely common condition with potentially serious consequences to long-term health. Between $50 \%$ and $90 \%$ of people with coeliac disease remain undiagnosed in the community with mild symptoms. The severity of symptoms varies widely from patient to patient, but there are only limited, unconvincing data available to link the severity of symptoms to the risk of developing long-term complications. Similarly, although there are good data to 


\section{Key references}

- Ferguson A, Arranz E, O'Mahony S. Clinical and pathological spectrum of coeliac disease: active, silent, latent and potential. Gut 1993;34:150-1.

- Hallert C, Lohiniemi S. Quality of life of coeliac patients living on a gluten-free diet. Nutrition 1999;15:795-7.

- Holmes GKT, Prior P, Lane MR, et al. Malignancy in coeliac disease, effect of a gluten free diet. Gut 1989;30:333-8.

- Smedby KE, Akerman M, Hildebrand $H$, et al. Malignant lymphomas in coeliac disease: evidence of increased risks for lymphoma types other than enteropathy-type T-cell lymphoma. Gut 2005;54:54-9.

- Moreno ML, Vazquez H, Mazure R, et al. Stratification of bone fracture risk in patients with celiac disease. Clin Gastroenterol Hepatol 2004;2:127-34.

suggest that long-term adherence to GFD will decrease the incidence of complications in the overtly symptomatic patients, there is much less to show that patients with few symptoms have the same benefit.

Starting a patient on a GFD should not be undertaken lightly. Doctors need to be sure that the treatments they are offering are doing more good than harm. In many patients with coeliac disease the decision to start a GFD is easy to make. However, in minimally symptomatic and asymptomatic patients, this decision is more difficult than it first appears. It might be hypothesised that the large subgroup of patients with "mild" disease will not develop long-term complications and therefore do not need treatment or followup. On the other hand, this group might be at equal risk, in which case then perhaps a population screening programme is indicated. These and other issues fuel the debate on screening whole populations for coeliac disease. ${ }^{104} 105$ Further research needs to be conducted to identify which patients with coeliac disease are most at risk of developing complications so that the limited resources available can be concentrated on those who will have greatest benefit. Also, the purpose of treatment needs further clarification. Obviously a GFD is aimed at improving symptoms but the doctors should also aim to prevent complications.

Although superficially the treatment of coeliac disease with GFD appears to be simple, there are many areas where common, accepted clinical practice is not backed by an adequate evidence base. With an increasing number of minimally symptomatic patients appearing in gastroenterology clinics, many issues on their treatment need clarification.

\section{MULTIPLE CHOICE QUESTIONS (TRUE (T)/FALSE (F));}

\section{ANSWERS AFTER THE REFERENCES}

\section{The following statements regarding coeliac disease} are true:

(A) Most patients are symptomatic at diagnosis

(B) IgA antigliadin antibody is the most accurate serological test

(C) The classic presentation of malabsorption was first described by Gee in the 1940s

(D) To develop coeliac disease, a person has to have a genetic predisposition

(E) A gluten-free diet (GFD) can contain oats

\section{In coeliac disease:}

(A) Quality of life is always improved with a GFD

(B) Untreated patients have a normal life expectancy

(C) Suicide is less common than in the general population

(D) Survival is improved with strict adherence to a GFD

(E) There is an excess mortality in those presenting with malabsorption

\section{The following statements regarding malignancy are true:}

(A) Colorectal carcinoma is more common in patients with untreated coeliac disease

(B) The relative risk of enteropathy-associated lymphoma in coeliac disease is $5-100$

(C) Small-bowel adenocarcinoma is more common in patients with coeliac disease

(D) Malignancy is not associated with dermatitis herpetiformis

(E) Strict adherence to a GFD for $>5$ years seems to protect against malignancy

\section{With regard to bone mineral density in coeliac disease:}

(A) A third of patients have osteoporosis at the time of diagnosis of coeliac disease

(B) Low bone mineral density does not occur in children with undiagnosed disease

(C) A GFD does not protect against fractures

(D) The most rapid rise in bone mineral density occurs in the first 12 months of treatment with a GFD

(E) Low bone mineral density may be due to osteomalacia

\section{In coeliac disease:}

(A) Infertility occurs only in women

(B) Women are likely to have a later menopause

(C) Recurrent abortions are unlikely before diagnosis

(D) Fathers with coeliac disease may have small birthweight babies

(E) $50 \%$ of men have poor semen quality

\section{Authors' affiliations}

C J R Goddard, H R Gillett, St John's Hospital, Livingston, West Lothian, UK Competing interests: None declared.

\section{REFERENCES}

1 Gee S. On the coeliac affection. St Barth Hosp Rep 1888;24:17-20.

2 Dicke WK, Weijers HA, van de Kamer JH. Coeliac disease II: the presence in wheat of a factor having deleterious effect in cases of celiac disease. Acta Paediatr Scand 1953;42:34-42.

3 Ferguson A, Arranz E, O'Mahony S. Clinical and pathological spectrum of coeliac disease: active, silent, latent and potential. Gut 1993;34:150-1.

4 Ivarsson A, Persson LA, Juto P, et al. High prevalence of coeliac disease in adults: a Swedish population-based study. J Intern Med 1999;245:63-8.

5 Carlsson AK, Axelsson IE, Borulf SK, et al. Serological screening for celiac disease in healthy 2.5 -year-old children in Sweden. Pediatrics $2001 ; 107: 42-5$

6 Collin P, Rennala T, Rasmussen M, et al. High incidence and prevalence of adult coeliac disease. Augmented diagnostic approach. Scand J Gastroenterol 1997;32:1129-33.

7 Kolho KL, Farkkila MA, Savilahti E. Undiagnosed coeliac disease is common in Finnish adults. Scand J Gastroenterol 1998;33:1280-3.

8 Hovdenak N, Hovlid E, Aksnes L, et al. High prevalence of asymptomatic coeliac disease in Norway: a study of blood donors. Eur J Gastroenterol Hepatol 1999;11:185-7.

9 Rostami K, Mulder CJ, Were JM, et al. High prevalence of celiac disease in apparently healthy blood donors suggests a high prevalence of undiagnosed 
celiac disease in the Dutch population. Scand J Gastroenterol 1999;34:276-9

10 Catassi C, Fabiani E, Ratsch IM, et al. Celiac disease in the general population: should we treat asymptomatic cases. J Paediatr Gastroenterol Nutr 1997:24:S10-13.

11 Volta U, Bellentani S, Bianchi FB, et al. High prevalence of celiac disease in Italian general population. Dig Dis Sci 2001;46:1500-5.

12 Reistra S, Fernandez E, Rodrigo L, et al. Prevalence of coeliac disease in the general population of northern Spain. Strategies of serologic screening. Scand I Gastroenterol 2000;35:398-402.

13 Johnston SD, Watson RG, McMillan SA, et al. Coeliac disease detected by screening is not silent-simply unrecognised. Q J Med 1998;91:853-60.

14 Cook HB, Burt MJ, Colleft JA, et al. Adult coeliac disease: prevalence and clinical significance. J Gastroenterol Hepatol 2000;15:1032-6.

15 Gomez JC, Selvaggio GS, Viola M, et al. Prevalence of celiac disease in Argentina: screening of an adult population in the La Plate area. Am J Gastroenterol 2001;96:2700-4

16 Gandolfi L, Pratesi R, Cordoba JC, et al. Prevalence of celiac disease among blood donors in Brazil. Am J Gastroenterol 2000:95:689-92.

17 Green PHR, Stavropoulos SN, Panagi SG, et al. Characteristics of adult celiac disease in the USA: results of a national survey. Am J Gasroenterol 2001;96:126-31

18 Ferguson A, Kingston K. Coeliac disease and malignancies. Acta Paediatr 1996;412(Suppl): 78-81.

19 Collin P, Reunala T, Pukkala E, et al. Coeliac disease-associated diseases and survival. Gut 1994;35:1215-18.

20 Collin P, Pukkala E, Reunala T. Malignancy and survival in dermatitis herpetiformis: a comparison with coeliac disease. Gut 1996:38:528-30.

21 Delco F, El-Serag HB, Sonnenberg A. Celaic sprue among US military veterans: associated disorders and clinical manifestations. Dig Dis Sci 1999:44:966-72

22 Lewis HM, Reunala TL, Garioch JN, et al. Protective effect of gluten-free diet against development of lymphoma in dermatitis herpetiformis. $\mathrm{Br} J$ Dermatol 1996;135:363-7.

23 Sigurgeirsson B, Agnarsson BA, Lindelof B. Risk of lymphoma in patients with dermatitis herpetiformis. BMJ 1994;308:13-15.

24 Swinson CM, Coles EC, Slavin G, et al. Coeliac disease and malignancy. Lancet 1983:1:111-15.

25 Cooper B, Holmes GKT, Cooke W. Lymphoma risk in coeliac disease of later life. Digestion 1982;23:89-92.

26 Holmes GKT, Prior $P$, Lane MR, et al. Malignancy in coeliac disease, effect of a gluten free diet. Gut 1989;30:333-8.

27 Selby WS, Gallagher ND. Malignancy in a 19-year experience of adult coeliac disease. Dig Dis Sci 1979;24:648-8.

28 Catassi C, Fabiani E, Corrao G, et al. Risk of non-Hodgkin lymphoma in celiac disease. JAMA 2002:287:1413-19.

29 Hawkes ND, Swift GL, Smith PM, et al. Incidence and presentation of coeliac disease in South Glamorgan. Eur J Gastroenterol Hepatol 2000; 12:345-9.

30 Schober E, Bittmann B, Granditsch G, et al. Screening by anti-endomysium antibody for celiac disease in diabetic children and adolescents in Austria. I Pediatr Gastroenterol Nutr 2000:30:391-6.

31 Carnicer J, Farre C, Varea V, et al. Prevalence of coeliac disease in Down's syndrome. European J Gastroenterol Hepatol 2001;13:263-7.

32 Gilleft PM, Gillett HR, Israel DM, et al. Increased prevalence of celiac disease in girls with Turner syndrome detected using antibodies to endomysium and tissue transglutaminase. Can J Gastroenterol 2000;14:915-18.

33 Ivarsson SA, Carlsson A, Bredberg A, et al. Prevalence of coeliac disease in Turner syndrome. Acta Paediatr 1999;88:933-6.

34 Giannotti A, Tiberio G, Castro M, et al. Coeliac disease in Williams syndrome. J Med Genet 2001:38:767-8.

35 Ivarsson A, Persson LA, Nystrom L, et al. Epidemic of coeliac disease in Swedish children. Acta Paediatr 2000;89:165-71.

36 Ivarsson A, Hernell $\mathrm{O}$, Stenlund $\mathrm{H}$, et al. Breast feeding protects against celiac disease. Am J Clin Nutr 2002;75:914-21.

37 Catassi C, Ratsch I-M, Fabiani E, et al. Coeliac disease in the year 2000; exploring the iceberg. Lancet 1994;343:200-3.

$38 \mathrm{Hin} H$, Bird G, Fisher $\mathrm{P}$, et al. Coeliac disease in primary care: case finding study. BMJ 1999:318:164-7.

39 Bottaro G, Cataldo F, Rotolo N, et al. The clinical pattern of subclinical/silent celiac disease: an analysis on 1026 consecutive cases. Am J Gastroenterol 1999;94:691-6.

40 Hallert C, Granno C, Grant C, et al. Quality of life of adult coeliac patients treated for 10 years. Scand J Gastroenterol 1998;33:933-8.

41 Hallert C, Lohiniemi S. Quality of life of coeliac patients living on a glutenfree diet. Nutrition 1999:15:795-7.

42 Ciacci C, lavarone A, Mazzacca G, et al. Depressive symptoms in adul coeliac disease. Scand J Gastroenterol 1998;33:247-50.

43 Addolorato G, Capristo E, Ghittoni G, et al. Anxiety but not depression decreases in coeliac patients after one-year gluten-free diet: a longitudinal study. Scand J Gastroenterol 2001;36:502-6.

44 Neilsen $\mathrm{OH}$, Jacobsen O, Pedersen EF, et al. Non-tropical sprue: malignant diseases and mortality rate. Scand J Gastroenterol 1985;20:13-18.

45 Logan RF, Rifkind EA, Turner ID, et al. Mortality in celiac disease. Gastroenterology 1989;97:265-71.

46 Corrao G, Corrazza GR, Bagnardi V, et al. Mortality in patients with coeliac disease and their relatives: a cohort study. Lancet 2001;358:356-61.

47 Holmes GKT, Stokes PL, Sorahan TM, et al. Coeliac disease, gluten free diet and malignancy. Gut 1976;17:612-19.

48 Card TR, West J, Holmes GK. Risk of malignancy in diagnosed coeliac disease: a 24-year prospective, population-based, cohort study. Aliment Pharmacol Ther 2004:20:769-75.
49 Freeman $\mathrm{HJ}$. Lymphoproliferative and intestinal malignancies in 214 patients with biopsy-defined celiac disease. J Clin Gastroenterol 2004;38:429-34.

50 Smedby KE, Akerman M, Hildebrand $\mathrm{H}$, et al. Malignant lymphomas in coeliac disease: evidence of increased risks for lymphoma types other than enteropathy-type T cell lymphoma. Gut 2005;54:54-9.

51 Leonard JN, Tucker WFG, Fry JS, et al. Increased risk of malignancy in dermatitis herpetiformis. BMJ 1983;286:16-18.

52 Cellier C, Delabesse E, Helmer C, et al. Refractory sprue, coeliac disease and enteropathy-associated T-cell lymphoma. Lancet 2000;356:203-8.

53 Egan L, Walsh SV, Stevens FM, et al. Coeliac associated lymphoma. J Clin Gastroenterol 1995;21:123-9.

54 Pricolo VE, Mangi AA, Aswad B, et al. Gastrointestinal malignancies in patients with celiac sprue. Am J Surg 1998:176:344-7.

55 Wright DH, Jones DB, Clark $\mathrm{H}$, et al. Is adult-onset coeliac disease due to a low-grade lymphoma of intraepithelial lymphocytes? Lancet 1991;337:1373-4.

56 Valdmarsson $T$, Lofman $O$, Toss $G$, et al. Reversal of osteopenia with diet in adult coeliac disease. Gut 1996;38:322-7.

57 Kemppainen $\mathrm{T}$, Kroger $\mathrm{H}$, Janatuinen $\mathrm{E}$, et al. Osteoporosis in adult patients with coeliac disease. Bone 1999;24:249-55

58 Meyer D, Stavropolous S, Daimond B, et al. Osteoporosis in a North American adult population with celiac disease. Am J Gastroenterol 2001;96:112-19

59 Sategna-Guidetti C, Grosso SB, Grosso S, et al. The effects of 1-year gluten withdrawal on bone mass, bone metabolism and nutritional status in newly diagnosed adult coeliac disease patients. Aliment Pharm Ther 2000;14:35-43

60 Pistorius LR, Sweidan WH, Purdie DW, et al. Coeliac disease and bone mineral density in adult female patients. Gut 1995;37:639-42.

61 McFarlane XA, Bhalla AK, Reeves DE, et al. Osteoporosis in adult coeliac disease. Gut 1995;36:710-14.

62 Mora S, Barera G, Ricotti A, et al. Reversal of low bone density with a glutenfree diet in children and adolescents with celiac disease. Am J Clin Nutr 1998:67:477-81.

63 Valdimarsson T, Toss $G$, Ross I, et al. Bone mineral density in coeliac disease. Scan J'Gastroenterol 1994;29:457-61.

64 Scotta MS, Salvatore S, Salvatoni A, et al. Bone mineralization and body composition in young patients with celiac disease. Am J Gastroenterol 1997;92:1331-4

65 Kemppainen $\mathrm{T}$, Kroger $\mathrm{H}$, Janatuinen $\mathrm{E}$, et al. Bone recovery after a glutenfree diet: a 5-year follow-up study. Bone 1999;25:355-60.

66 Mora S, Barera G, Beccio S, et al. Bone density and bone metabolism are normal after long-term gluten-free diet in young celiac patients. Am J Gastroenterol 1999:94:398-403.

67 Di Stephano M, Veneto G, Corrao G, et al. Role of lifestyle factors in the pathogenesis of osteopenia in adult coeliac disease: a multivariate analysis. Eur J Gastroenterol Hepatol 2000;12:1195-9.

68 Kavak US, Yuce A, Kocak N, et al. Bone mineral density in children with untreated and treated celiac disease. J Pediatr Gastroenterol Nutr 2003;37:434-6

69 Mather KJ, Meddings JB, Beck Pl, et al. Prevalence of IgA antiendomysia antibody in asymptomatic low bone mineral density. Am J Gastroenterol 2001;96:120-5.

70 Mazure R, Vazquez H, Gonzalez D, et al. Bone mineral affection in asymptomatic adult patients with celiac disease. Am J Gastroenterol 1994;89:2130-4

71 Cummings SR, Black DM, Nevitt MC, et al. Bone density at various sites for prediction of hip fractures. The study of osteoporotic fractures research group. Lancet 1993;341:72-5.

72 Fickling WE, McFarlane XA, Bhalla AK, et al. The clinical impact of metabolic bone disease in coeliac disease. Postgrad Med J 2001;77:33-6.

73 Vasquez H, Mazure R, Gonzalez D, et al. Risk of fractures in celiac disease patients: a cross-sectional, case controlled study. Am J Gastroenterol 2000;95:183-9.

74 Thomason K, West J, Logan RFA, et al. Fracture experience of patients with celiac disease: a population based survey. Gut 2003;52:518-22

75 Vestergaard P, Mosekilde L. Fracure risk in patients with celiac disease, Crohn's disease and ulcerative colitis: a nationwide follow-up study of 16,416 patients in Denmark. Am J Epidemiol 2002;156:1-10.

76 Moreno ML, Vazquez H, Mazure R, et al. Stratification of bone fracture risk in patients with celiac disease. Clin Gastroenterol Hepatol 2004;2:127-34.

77 Ciacci C, Maurelli L, Klain M, et al. Effects of dietary treatment on bone mineral density in adults with celiac disease: factors predicting response. Am J Gastroenterol 1997:92:992-6.

78 Farthing MJG, Edwards CRW, Rees $\mathrm{LH}$, et al. Male gonadal function in coeliac disease: 1. Sexual dysfunction, infertility and semen quality. Gu 1982;23:608-14.

79 Ciacci C, De Rosa A, de Michele G, et al. Sexual behaviour in untreated and treated coeliac patients. Eur J Gastroenterol Hepatol 1998;10:649-51.

80 Moltini N, Bardella MT, Bianchi PA. Obstetric and gynaecological problems in women with untreated celiac sprue. J Clin Gastroenterol 1990;12:37-9.

81 Smecuol E, Maurino E, Vazquez H, et al. Gynaecological and obstetric disorders in coeliac disease: frequent clinical onset during pregnancy or the puerperium. Eur J Gastroenterol Hepatol 1996;8:63-9.

82 Collin P, Vilska S, Heinonen PK, et al. Infertility and coeliac disease. Gut 1996;39:382-4

83 Meloni GF, Dessole S, Vargiu N, et al. The prevalence of coeliac disease in infertility. Hum Reprod 1999;14:2759-61.

84 Ciacci C, Cirillo M, Auriemma G, et al. Celiac disease and pregnancy outcome. Am J Gastroenterol 1996:91.718-22. 
85 Martinelli P, Troncone R, Paparo F, et al. Coeliac disease and unfavourable outcome of pregnancy. Gut 2000;46:332-5.

86 Gasbarrini A, Sanz Torre E, Trivellini C, et al. Recurrent spontaneous abortion and intrauterine fetal growth retardation as symptoms of celiac disease. Lancet 2000;356:399-400.

87 Nørgård B, Fonager K, Sorensen HT, et al. Birth outcomes of women with celiac disease: a nationwide historical cohort study. Am J Gastroenterol 1999;94:2435-40.

88 Ludvigsson JF, Ludvigsson J. Coeliac disease in the father affects the newborn. Gut 2001;49:169-75.

89 Barker DJ. Fetal origins of coronary heart disease. BMJ 1995;311:171-4

90 Godfrey KM, Barker DJ. Fetal nutrition and adult disease. Am J Clin Nutr 2000;71:S1344-52.

91 Rich-Edwards JW, Colditz GA, Stampfer MJ, et al. Birthweight and the risk for type 2 diabetes in adult women. Ann Intern Med 1999;130:278-84.

92 Cinquetti M, Trabucchi C, Menegazzi N, et al. Psychological problems connected to the dietary restrictions in the adolescent with coeliac disease. Paediatria Med Chir 1999;21:279-83.

93 Read M, O'Halloran ET, O'Sullivan C. Coeliac disease in adolescents/young adults: difficulties in monitoring. Br J Biomed Sci 2000;57:217-20.

94 Fabiani E, Taccari LM, Rätsch IM, et al. Compliance with gluten-free diet in adolescents with screening-detected celiac disease: a 5-year follow-up study. J Pediatr 2000;136:841-3.

95 Janatuinen EK, Kemppainen TA, Pikkarainen PH, et al. Lack of cellular and humoral immunological responses to oats in adults with coeliac disease. Gut 2000;46:327-31.

96 Hoffenberg EJ, Haas J, Drescher A, et al. A trial of oats in newly diagnosed celiac disease. J Pediatr 2000;137:361-6.

97 Picarelli A, Di Tola M, Sabbatella L, et al. Immunologic evidence of no harmful effect of oats in celiac disease. Am J Clin Nutr 2001;74:137-40.

98 Thompson T. Questionable foods and the gluten-free diet: survey of current recommendations. J Am Diet Assoc 2000;100:463-5.
99 Faulkner-Hogg KB, Selby WS, Loblay RH. Dietary analysis in symptomatic patients with coeliac disease on a gluten-free diet: the role of trace amounts of gluten and non-gluten food intolerances. Scand J Gastroenterol 1999:34:784-9.

100 Fotoulaki M, Nousia-Arvanitakis S, Augoustidou-Savvopoulou P, et al. Clinical application of immunological markers as monitoring tests in celiac disease. Dig Dis Sci 1999;44:2133-8.

101 Dickey W, Hughes DF, McMillan SA. Disappearance of endomysial antibodies in treated celiac disease does not indicate histological recovery. Am J Gastroenterol 2000;95:712-14.

102 Selby WS, Painter D, Collins A, et al. Persistent mucosal abnormalities in coeliac disease are not related to the ingestion of trace amounts of gluten. Scand J Gastroenterol 1999;34:909-14.

103 Cummins AG, Thompson FM, Butler RN, et al. Improvement in intestinal permeability precedes morphometric recovery of the small intestine in coeliac disease. Clin Sci 2001;100:379-86.

104 Fasano A. Protagonist: European and North American populations should be screened for coeliac disease. Gut 2003;52:168-9.

105 Kumar PJ. Antagonist: European and North American populations should be screened for coeliac disease. Gut 2003;52:170-1.

\section{ANSWERS}

1. (A) $\mathrm{T}(\mathrm{B}) \mathrm{F}(\mathrm{C}) \mathrm{F}(\mathrm{D}) \mathrm{T}(\mathrm{E}) \mathrm{T}$

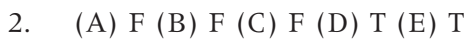

3. (A) $\mathrm{F}(\mathrm{B}) \mathrm{T}(\mathrm{C}) \mathrm{T}(\mathrm{D}) \mathrm{F}(\mathrm{E}) \mathrm{T}$

4. (A) $\mathrm{T}(\mathrm{B}) \mathrm{F}(\mathrm{C}) \mathrm{F}(\mathrm{D}) \mathrm{T}(\mathrm{E}) \mathrm{T}$

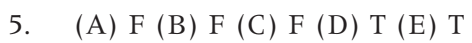

\section{BNF for Children 2006, second annual edition}

In a single resource:

- guidance on drug management of common childhood conditions

- hands-on information on prescribing, monitoring and administering medicines to children

- comprehensive guidance covering neonates to adolescents

For more information please go to bnfc.org 